\section{Perception and attitude of obstetric fistula patients about their condition: a report from the Regional Hospital Maroua, Cameroon}

\author{
Pierre Marie Tebeu, ${ }^{1,2,3}$ \\ Charles-Henry Rochat, ${ }^{4}$ \\ Jean Marie Kasia, ${ }^{3}$ Thérèse Delvaux ${ }^{5}$ \\ 'Department of Obstetrics and \\ Gynecology, Regional Hospital, Maroua, \\ Cameroon; 'Ligue d'Initiative et de \\ Recherche Active pour la Santé et \\ I'Education de la Femme (LIRASEF); \\ ${ }^{3}$ Department of Obstetrics and \\ Gynecology, University Hospitals, \\ Yaoundé, Cameroon; ${ }^{4}$ Geneva Foundation \\ for Medical Education and Research \\ (GFMER), Geneva, Switzerland; \\ ${ }^{5}$ Institute of Tropical Medicine, Antwerp, \\ Belgium
}

\section{Abstract}

Background. Obstetric fistula results in a continuous leakage of urine or feces through the vagina. The social consequences of obstetric fistula are severe, with affected women often ostracized from the community, divorced, abandoned and remaining childless.

Objective. The general objective of this study was to analyze the perception and attitude of obstetric fistula patients treated at the Regional Hospital of Maroua, Cameroon.

Design and Methods. This is a case series study of 42 obstetric fistula patients at the Regional Hospital of Maroua, Cameroon. After confirmation of the diagnosis of obstetric fistula, the patients were invited to participate to a survey prior to the surgical procedure, from May 2005 to August 2007.

Results. Thirty-two percent of patients (13/41) said that they used to isolate themselves. Fifteen percent of patients (6/41) cited suicide as a solution for their fistula problem. Among the 29 patients who had never been operated before, 12 (41\%) declared that this was due to a lack of financing means; eight (28\%) cited the lack of fistula treatment services; seven (24\%) said that this fistula was recent and 2 (7\%) declared that they did not consult before.

Conclusions. Obstetric fistula patients have a very negative perception about their condition. It is strongly recommended to improve the accessibility to maternal health program in order to prevent and manage the obstetric fistula in Far North Cameroon.

\section{Introduction}

Obstetric fistula results in a continuous leakage of urine or feces through the vagina. The social consequences are severe, with affected women often ostracized from the community, divorced, abandoned and remaining childless. The smell of urine or feces and continuous wetness are uncomfortable and humiliating. The social isolation compounds the affected woman's belief that she is a disgrace and brought shame to the family. Women with obstetric fistula are often solitary, eat alone, and are not allowed to cook for others. ${ }^{1}$

The general purpose of this study was to describe and get a better understanding of the perception and attitude of obstetric fistula patients treated at the Regional Hospital of Maroua, Cameroon.

\section{Design and Methods}

We reported about a case series study conducted at the Regional Hospital of Maroua, Cameroon, which is the second level referral hospital for the Far North Region. Women consulted at Maroua Regional Hospital Cameroon for leakage of urine or stsools through the vagina. After the diagnosis of obstetric fistula was confirmed, patients were invited to participate to a survey prior to the surgical procedure, from May 2005 to August 2007. After a verbal consent was obtained, an assistant nurse explained the purpose of the survey to the patient. Forty-two women were identified with obstetric fistula. Data about previous treatment, the perception and attitude of patients about their condition and their lifestyle were collected through a structured questionnaire. Descriptive analysis was performed using EPI Info 3.4.

\section{Results}

Perception and attitude of obstetric fistula patients about their condition

Among the 42 patients, 24 (57\%) said they did not believe that genital fistula was curable. While 29 (69\%) patients reported no previous attempt of operating the obstetric fistula, 13 (31\%) patients had been operated in the past. A majority (93\%) reported talking with the family about the fistula. Thirty-two percent of patients (13/41) said that they used to isolate themselves. Fifteen percent of patients (6/41) cited suicide as a solution for their fistula problem (Table 1).
Correspondence: Pierre Marie Tebeu, Department of Obstetrics and Gynecology, University Hospitals, Yaoundé, Cameroon.

Tel. +237.77 .675533$

E-mail: pmtebeu@yahoo.fr

Key words: obstetric fistula, perception, attitude, Maroua, Cameroon-

Contributions: PMT, study concept, design, data collection, statistical analysis, manuscript writing, and review; CHR, study conception, manuscript writing, and review; KJM, manuscript writing and review, TD, manuscript writing and review.

Received for publication: 3 October 2010. Accepted for publication: 13 December 2010.

This work is licensed under a Creative Commons Attribution 3.0 License (by-nc 3.0).

(C) Copyright P.M. Tebeu et al., 2010

Licensee PAGEPress, Italy

Urogynaecologia 2010; 24:e2

doi:10.4081/uij.2010.e2

\section{Reasons for no previous intervention}

Among the 29 patients who had never been operated before, 12 (41\%) declared that this was because of lack of financing means; eight (28\%) patientes cited the lack of fistula treatment services; seven (24\%) patients said this fistula was recent and 2 (7\%) declared that they did not consult before (Table 2).

\section{Discussion}

Among the 42 patients, 24 (57\%) said they did not believe that the fistula was curable, showing that there is a lack of information about the possibility of treatment of the obstetric fistula. Nevertheless, complete cure with good continence at primary surgery of up to $92 \%$ of patients are reported by some studies. ${ }^{2}$ This means that in addition to making care accessible, an information campaign regarding the fistula condition and its treatment is needed. Among the 29 patients without any previous attempt of intervention, the reason given for delaying the surgery by 4 out of 10 patients was the lack of financing means. The cost of obstetric fistula treatment including surgery, follow-up, medical and surgical supplies is estimated at up to US\$400, with additional cost for transport and lodging. ${ }^{1}$ In Far North Cameroon, interventions for obstetric fistulas have been possible because of the technical and financial support from the Geneva Foundation for Medical Education and Research (GFMER). In Africa, up to $87 \%$ of obstetric fistula patients are divorced and up to 
Table 1. Perception and attitude of patients.

\begin{tabular}{|c|c|c|}
\hline Patients characteristics & $\begin{array}{l}\text { Obstet } \\
\text { n/N }\end{array}$ & $\begin{array}{c}\mathrm{N}=42 \\
\%\end{array}$ \\
\hline $\begin{array}{l}\text { Believe that the disease is curable } \\
\text { No } \\
\text { Yes }\end{array}$ & $\begin{array}{l}24 / 42 \\
18 / 42\end{array}$ & $\begin{array}{l}57.1 \\
42.9\end{array}$ \\
\hline $\begin{array}{l}\text { Any previous attempt of operation of the fistula } \\
\text { No } \\
\text { Yes }\end{array}$ & $\begin{array}{l}29 / 42 \\
13 / 42\end{array}$ & $\begin{array}{l}69.0 \\
31.0\end{array}$ \\
\hline $\begin{array}{l}\text { Talked about fistula with the family } \\
\text { Yes } \\
\text { No }\end{array}$ & $\begin{array}{c}38 / 41 \\
3 / 41\end{array}$ & $\begin{array}{c}92.7 \\
7.3\end{array}$ \\
\hline $\begin{array}{l}\text { Use to isolate themselves } \\
\text { No } \\
\text { Yes }\end{array}$ & $\begin{array}{l}28 / 41 \\
13 / 41\end{array}$ & $\begin{array}{l}68.3 \\
31.7\end{array}$ \\
\hline $\begin{array}{l}\text { Ever thought of attempting suicide } \\
\text { No } \\
\text { Yes }\end{array}$ & $\begin{array}{c}35 / 41 \\
6 / 41\end{array}$ & $\begin{array}{l}85.4 \\
14.6\end{array}$ \\
\hline
\end{tabular}

Table 2. Reasons for having never been operated.

\begin{tabular}{lcc} 
Reasons & $\begin{array}{c}\text { Obstetric fistula patients never operated }(\mathrm{N}=29) \\
\mathrm{n} / \mathrm{N}\end{array}$ & $\%$ \\
Lack of financing means & $12 / 29$ & 41.4 \\
Lack of fistula treatment services & $8 / 29$ & 27.6 \\
\hline Recent fistula & $7 / 29$ & 24.1 \\
No previous consultation & $2 / 29$ & 6.9 \\
\hline
\end{tabular}

$54 \%$ of them have no kind of income; yet even those having an income are still very poor, as the occupations are always farming. ${ }^{3}$ Finally, obstetric fistula patients are mostly poor and this underlying condition lead to their inability to pay for their operation. The lack of fistula treatment services, cited by about a fourth of patients as a reason for not having been previously operated, suggests that there is a need for at least one permanent surgeon trained on obstetric fistula at the Regional level in Cameroon and that the medical staff all over the Region should be informed on the availability of the services in order to refer the patients to the hospital. This should be the same for other developing countries, as WHO stressed the presence of skilled staff for fistula operation and service delivery, as some of its indicators for monitoring and evaluating the fistula program. 'Thirty-two percent of patients (13/41) said that they used to have a solitary life. This observation was also made in Eritrea where a patient (32-year-old woman living with fistula for 17 years and have 2 living children) made the following declaration: I cannot go out into the community. I cannot talk about. I have to wear a pad all the time. I sleep in a separate bed from my husband. My husband does not complain. I don't feel comfortable having sex. I refuse my husband sometimes. ${ }^{4}$

Fifteen percent of patients (6/41) suggested that suicide seemed to be the solution to their fistula problem. A higher rate of thinking of suicide (38\%) was recently reported among patients with genital fistula in Ethiopia. ${ }^{5}$ These observations are in line with recent findings among non-fistula women at Maroua Regional Hospital in Far North Region. ${ }^{6}$ Among 96 women interviewed about the attitude towards obstetric fistula, 33\% of them said they would hide themselves and $10 \%$ said they would consider committing suicide. Obstetric fistula is a chronic condition in a setting like Far North of Cameroon, where surgery for treating this con- dition was not available before the present program, and $60 \%$ of patients experienced fistula for more than five years.

\section{Conclusions}

Obstetric fistula patients have a very negative perception and attitude about their condition. It is therefore strongly recommended to improve the quality and the accessibility to maternal health program in order to prevent and timely multidisciplinary manage the obstetric fistula in Far North Cameroon.

\section{References}

1. WHO. 2006. Geneva: Obstetric fistula. Guiding principles for clinical management and programme development. Available at URL: http://www.who.int/reproductivehealth/ publications/maternal_perinatal_health/924 1593679/en/index.html

2. Muleta M. Obstetric fistula in developing countries: a review article. J Obstet Gynaecol Can 2006;28:962-6.

3. Meyer L, Ascher-Walsh CJ, Norman R, Idrissa A, Herbert $\mathrm{H}$, Kimso 0 et al. Commonalities among women who experienced vesicovaginal fistulae as a result of obstetric trauma in Niger: results from a survey given at the National Hospital Fistula Center, Niamey, Niger. Am J Obstet Gynecol 2007;197:90.e1-4.

4. Turan JM, Johnson K, Polan ML. Experience of women seeking medical care for obstetric fistula in Eritrea: Implications for prevention, treatment, and social reintegration. Glob Public Health 2007;2:64-77.

5. Goh JT, Sloane KM, Krause HG, Browning A, Akhter S. Mental health screening in women with genital tract fistulae. BJOG 2005;112: 1328-30.

6. Tebeu PM, de Bernis L, Boisrond L, Le Duc A, Mbassi AA, Rochat CH. Knowledge, attitude and perception about obstetric fistula by Cameroonian women. Prog Urol 2008; 18:379-89. 